\title{
Complicaciones en el uso del colgajo TRAM pediculado para reconstrucción mamaria por cáncer
}

\section{Complications in breast reconstruction with pedicled TRAM flap}

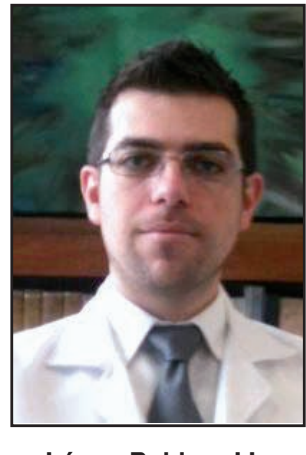

\author{
López-Robles, J.L.*, Gutiérrez-Salgado, J.E. **, Dávila-Díaz, R. ${ }^{\star \star *}$, \\ Poucel-Sánchez-Medal, F.****, Barrera-Fuentes, M. ${ }^{* \star * *}$
}

López-Robles, J.L.

\section{Resumen}

Las opciones en reconstrucción mamaria tras tratamiento oncoquirúrgico incluyen el uso de técnicas con implantes, el uso de colgajos autólogos y la combinación de ambos métodos. A nivel internacional, la reconstrucción con tejidos autólogos es el estándar de oro para la reconstrucción mamaria y específicamente, la utilización del colgajo miocutáneo de recto abdominal (colgajo TRAM) pediculado es una de las opciones más empleadas.

El presente estudio define con qué frecuencia se presentaron complicaciones tras la cirugía con colgajo TRAM pediculado para reconstrucción mamaria por cáncer en el Servicio de Cirugía Plástica y Reconstructiva del Hospital Central Sur de Alta Especialidad (PEMEX) de la Cuidad de México (México), en un periodo de estudio de 7 años. Además, se identifican los factores de riesgo que influyeron sobre la aparición de dichas complicaciones.

Diseñamos un estudio descriptivo, observacional y retrospectivo, que incluyó a 71 pacientes, de las cuales el 59.15\% presentaron alguna complicación. La mayoría de dichas complicaciones fueron menores (54.9\%) y tan solo 3 pacientes presentaron alguna complicación mayor $(4.2 \%)$. La complicación del sitio donante del colgajo más frecuente fue la aparición de hernia abdominal $(9.86 \%)$. La complicación más frecuente del colgajo y del sitio receptor fue la necrosis grasa parcial (23.94\%). Las únicas complicaciones sistémicas fueron atelectasia y tromboembolismo pulmonar, con 1 caso de cada. En el análisis bivariado, las pacientes fumadoras tuvieron un $40 \%$ más riesgo de presentar una complicación del colgajo en comparación con las no fumadoras $(\mathrm{p}=0.041)$. Las pacientes sometidas a radioterapia tuvieron un incremento del $30 \%$ en las complicaciones totales en comparación con las no radiadas $(\mathrm{p}=0.021)$. Al comparar el hecho de recibir quimioterapia o no y la presencia de necrosis grasa, el $32 \%$ de las pacientes tuvo esta complicación en comparación con el 10\% de las que no la recibieron con una diferencia estadísticamente significativa $(\mathrm{p}=0.047)$.

El colgajo TRAM pediculado sigue siendo, en nuestra práctica habitual, de elección en reconstrucción mamaria, considerándolo un procedimiento mayor no exento de complicaciones. Afortunadamente, la mayoría de ellas son menores y su frecuencia en nuestro hospital, es consistente con lo publicado en la literatura internacional.

Palabras clave Reconstrucción mamaria, Colgajo pediculado, Colgajo TRAM, Complicaciones postoperatorias.

Código numérico 5214-52140-158332
Abstract

Options for breast reconstruction after oncologic treatment include the use of prosthetic materials, autologous tissues, as well as a combination of both Worldwide, autologous breast reconstruction remains the gold standard, and Transverse Rectus Abdominis Muscle flap (TRAM flap), one of the most frequent choices.

The present study determines the frequency of complications after breast reconstruction with pedicled TRAM flap at the Plastic and Reconstructive Department of the Hospital Central Sur de Alta Especialidad de Petróleos Mexicanos in Mexico City (México). A period of 7 years was reviewed. In addition, risk factors that influenced the occurrence of such complications were analyzed. We designed an observational, descriptive and retrospective study that included 71 patients. Overall, 59.15\% patients presented at least one complication. Most of these were considered minor $(54.9 \%)$ and only 3 patients had a major complication $(4.2 \%)$. The most common donor site complication was abdominal hernia $(9.86 \%)$. The most frequent flap complication was partial fat necrosis $(23.94 \%)$. The only 2 systemic complications were atelectasis and pulmonary embolism, with 1 case each.

Bivariate analysis showed that smoking elevated $40 \%$ the risk for a flap complication $(\mathrm{p}=0.041)$. Patients with radiation therapy had a $30 \%$ increase in total complications $(\mathrm{p}=0.021)$. Thirty-two of the patients that received chemotherapy presented with fat necrosis while only $10 \%$ of the patients that did not receive chemotherapy had that problem $(\mathrm{p}=0.047)$.

The use of pedicled TRAM flap remains so far the gold standard in breast reconstruction in our practice and as a major procedure, some complications may be expected, mostly minor. The results in our hospital are consistent with reports in the international literature. $\begin{aligned} \text { Key words } & \text { Breast reconstruction, } \\ & \text { Pedicled flap, TRAM flap, } \\ & \text { Postoperative complications }\end{aligned}$

Numeral Code 5214-52140-158332

* Cirujano Plástico. Hospital Ángeles Culiacán. Culiacán, México.

** Cirujano Plástico. Hospital Central Sur de Alta Especialidad de Petróleos Mexicanos. Profesor del Curso de Cirugía Plástica y Reconstructiva de la Universidad Nacional Autónoma de México, México DF, México.

*** Cirujano Plástico. Hospital Ángeles del Pedregal. Hospital Central Sur de Alta Especialidad de Petróleos Mexicanos, México DF, México.

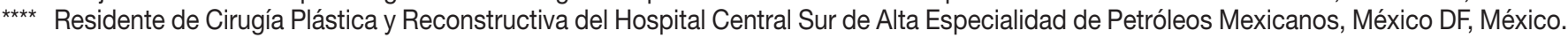

${ }^{\star * \star \star \star}$ Anestesióloga y Master en Ciencias. Instituto Nacional de Pediatría. México DF, México. 


\section{Introducción}

Las opciones de reconstrucción mamaria tras tratamiento oncoquirúrgico incluyen el uso de técnicas con implantes, colgajos autólogos, así como una combinación de ambos métodos. A nivel internacional, la reconstrucción con tejidos autólogos es el estándar de oro para la reconstrucción mamaria y específicamente, la utilización del colgajo miocutáneo de recto abdominal (colgajo TRAM por sus siglas en inglés Transverse Rectus Abdomini Muscle Flap) pediculado, es una de las opciones más empleadas. Nuestro Servicio de Cirugía Plástica y Reconstructiva del Hospital Central Sur de Alta Especialidad (PEMEX) de la Cuidad de México (México), no es la excepción, por lo que una buena parte de las reconstrucciones mamarias que realizamos, corresponden al procedimiento de rotación de colgajo TRAM pediculado. Es una técnica que ha pasado la prueba del tiempo, aún sin decaer en los centros más avanzados de tratamiento integral de cáncer mamario en el mundo, a pesar de las numerosas técnicas y variaciones microquirúrgicas surgidas en los últimos años. Sus ventajas están bien documentadas e incluyen una excelente simetría, contorno y apariencia estética de la mama reconstruida, no requiere técnicas microquirúrgicas y produce alto nivel de satisfacción en las pacientes (1).

Afortunadamente, son raras las complicaciones serias resultantes de una reconstrucción con colgajo TRAM y, en su mayoría se deben a enfermedades concomitantes. Es por ello que debemos realizar siempre una historia clínica y una exploración física detalladas para identificar y minimizar los riesgos.

Diversos autores (2-9) recogen complicaciones en sus series de pacientes sometidas a reconstrucción con colgajo TRAM; sin embargo, dichos estudios presentan resultados muy variables. Esta variabilidad podría deberse a diversas causas, entre ellas: el diseño del estudio, las diferencias en la población estudiada, la distinta definición operacional de las variables o diferencias en la técnica quirúrgica, entre otras. Además, ningún estudio de los revisados toma en cuenta todas las complicaciones posibles.

Las complicaciones más comunes de la reconstrucción con TRAM pueden dividirse en complicaciones del colgajo y complicaciones del sitio donante. Además pueden aparecer complicaciones sistémicas. Las complicaciones del colgajo incluyen: necrosis grasa parcial, necrosis cutánea parcial, necrosis total del colgajo TRAM (fallo o pérdida total del colgajo). Las complicaciones del sitio donante son: seroma, hematoma, dehiscencia de la herida, cicatriz patológica (hipertrófica o queloide), laxitud aponeurótica con abultamiento de la pared abdominal, hernia abdominal, necrosis del colgajo de la abdominoplastia e infección local. Entre las posibles complicaciones sistémicas que pueden añadirse encontramos: atelectasia pulmonar, tromboembolismo pulmonar y trombosis venosa profunda. Las pacientes con cáncer mamario tienen mayor riesgo de sufrir una trombosis venosa profunda, por lo que debemos instaurar siempre el uso de medidas profilácticas antes, durante y después de la cirugía.

Nuestro trabajo trata de definir con qué frecuencia se presentan complicaciones tras la cirugía con colgajo TRAM pediculado para reconstrucción mamaria por cáncer en el Servicio de Cirugía Plástica y Reconstructiva del Hospital Central Sur de Alta Especialidad (PEMEX) de la Cuidad de México en un periodo de 7 años. Además, identifica los factores de riesgo que influyeron sobre la aparición de dichas complicaciones.

\section{Material y Método}

Diseñamos un estudio descriptivo, observacional y retrospectivo, en el que incluimos mujeres con antecedente de cáncer de mama sometidas a reconstrucción mamaria con colgajo TRAM pediculado en el periodo de tiempo comprendido entre el 1 enero del 2004 y el 31 de diciembre del 2010 en el Servicio de Cirugía Plástica y Reconstructiva del Hospital Central Sur de Alta Especialidad de PEMEX, en la Cuidad de México (México). Los criterios de exclusión fueron pacientes que no contaban con expediente clínico completo y pacientes cuya reconstrucción mamaria no fue por cáncer. Las variables analizadas fueron: seroma, hematoma, dehiscencia de he-

Tabla I. Datos demográficos

\begin{tabular}{|c|c|}
\hline $\begin{array}{c}\text { Variables } \\
\text { independientes }\end{array}$ & Resultado \\
\hline Edad & media 49 años, DE +/- 7 \\
\hline Peso & mediana 66 kg, mínimo 40, máximo 103 \\
\hline Talla & media $1.58 \mathrm{~m}, \mathrm{DE}+/-0.61$ \\
\hline IMC & media $27.26 \mathrm{~kg} / \mathrm{m} 2, \mathrm{DE}+/-4$ \\
\hline Días de estancia & mediana 9 días, mínimo 5, máximo 31 \\
\hline Tabaquismo & $9.8 \%(7 / 71)$ \\
\hline $\begin{array}{l}\text { Enfermedades } \\
\text { concomitantes }\end{array}$ & $11.26 \%(8 / 71)$ \\
\hline Lateralidad & $\begin{array}{l}\text { TRAM derecho } 39.44 \%(28 / 71) \text {, TRAM } \\
\text { izquierdo } 59.15 \%(42 / 71) \\
\text { TRAM bilateral1.4\% (1/71) }\end{array}$ \\
\hline $\begin{array}{l}\text { Cirugía abdominal } \\
\text { previa }\end{array}$ & $83.1 \%(59 / 71)$ \\
\hline Disección ganglionar & $95.77 \%(68 / 71)$ \\
\hline Radioterapia & $\begin{array}{l}35.21 \%(25 / 71) \text {. Preoperatoria } 7.04 \% \\
(5 / 71) \text {, postoperatoria } 26.76 \%(19 / 71) \text {, } \\
\text { ambas } 1.4 \%(1 / 71)\end{array}$ \\
\hline Quimioterapia & $\begin{array}{l}60.5 \%(43 / 71) \text {. Preoperatoria } 15.49 \% \\
(11 / 71) \text {, postoperatoria } 38.03 \%(27 / 71) \text {, } \\
\text { ambas } 7.04 \%(5 / 71)\end{array}$ \\
\hline Terapia hormonal & $\begin{array}{l}\text { 49.29\% (35/71). Anastrozol 8.4\% (6/71) } \\
\text { Tamoxifeno 33.8\% (24/71), } \\
\text { ambos } 7.04 \%(5 / 71)\end{array}$ \\
\hline
\end{tabular}


rida, cicatriz patológica, laxitud aponeurótica, hernia abdominal, necrosis del colgajo de la abdominoplastia, infección local, necrosis grasa parcial del colgajo, necrosis cutánea parcial del colgajo, necrosis total del colgajo, necrosis de los colgajos de mastectomía, atelectasia pulmonar, tromboembolismo pulmonar, trombosis venosa profunda, y días de estancia hospitalaria. Como variables independientes tuvimos en consideración: la edad, índice de masa corporal, tabaquismo, enfermedades concomitantes, cirugía abdominal previa, diagnóstico histopatológico, lateralidad, disección ganglionar axilar, radioterapia, quimioterapia y terapia hormonal.

Revisamos todos los expedientes clínicos y determinamos si cada una de estas variables era positiva o negativa en base a su definición operacional y a la descripción de la evolución clínica encontrada en las notas postoperatorias.

Empleamos estadística descriptiva para las variables clínicas y demográficas. Frecuencia y/o proporciones para las variables nominales u ordinales. Promedio y desviación estándar para las variables numéricas con distribución Gaussiana; mediana con valores mínimos y máximos cuando no tenga esta distribución. También la frecuencia de cada complicación.

La evaluación de los factores de riesgo se realizó por separado a través de un análisis uni y multivariado con un modelo de regresión logística de pasos ascendentes. Estimamos la razón de riesgo (RR) individual y global. Consideramos significativo un valor de $\mathrm{p}<0.05$. Utilizamos el paquete estadístico SPSS versión 13.0 y STATA 10.0 .

\section{RESULTADOS}

Analizamos un total de 71 pacientes a las que se les había practicado reconstrucción mamaria postcáncer con colgajo TRAM pediculado en el periodo de estudio de 7 años. Los datos demográficos se resumen en la Tabla I.

Observamos que la mayoría de las pacientes $(88 \%$, $\mathrm{n}=63$ ) no presentaban enfermedades concomitantes. La enfermedad más prevalente fue la hipertensión arterial presente en 5 pacientes. La mayoría tenían antecedente de al menos 1 cirugía abdominal previa (solo 12 pacientes, $16.9 \%$ no tenían este antecedente). La disección ganglionar se había realizado en 68 pacientes $(95 \%)$.

En la mayoría $(\mathrm{n}=46,64 \%$, no se utilizó radioterapia, y en las que se realizó, en la mayoría $(n=19,26 \%$, fue postoperatoria seguidas por un $7 \%(\mathrm{n}=5)$ que la recibieron en el preoperatorio; solo 1 paciente recibió tanto en el pre como en el postoperatorio.

En cuanto a la quimioterapia, 28 pacientes (39\%) no la recibieron. De las que sí, en la mayoría fue postoperatoria (27 pacientes, 38\%), en 11 (15\%) fue preoperatoria y en $5(7 \%)$ fue tanto pre como postoperatoria.

Aproximadamente la mitad de las pacientes recibieron terapia hormonal, la mayoría (24 pacientes, $33.8 \%$ ) recibió Tamoxifeno, seguido de Anastrozol en 6 pacientes (8.4\%); 5 pacientes (7\%) recibió ambos medicamentos.
Tabla II. Frecuencia de aparición de complicaciones mayores y menores.

\begin{tabular}{|l|c|c|}
\hline \multicolumn{1}{|c|}{ Complicación } & Frecuencia & $\begin{array}{c}\text { Número de } \\
\text { pacientes }\end{array}$ \\
\hline Ninguna complicación & $40.85 \%$ & 29 \\
\hline Alguna complicación & $59.15 \%$ & 42 \\
\hline - Menor & $54.90 \%$ & 39 \\
\hline - Mayor & $4.20 \%$ & 3 \\
\hline
\end{tabular}

Gráfico 1. Frecuencia de complicaciones mayores y menores
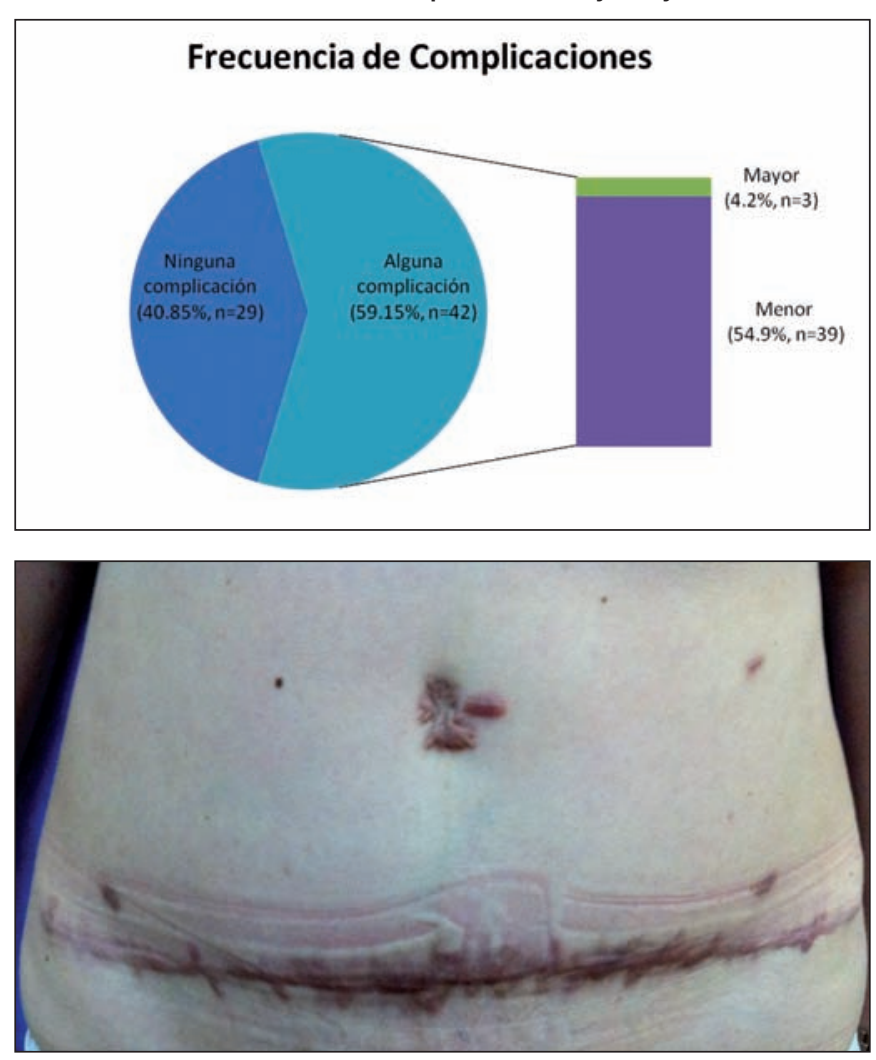

Fig. 1. Paciente de 48 años que desarrolla cicatriz patológica queloide de sitio donante 10 meses después de la realización de colgajo TRAM pediculado.

En total, 42 de las pacientes $(59.15 \%)$ presentaron alguna complicación. La mayoría de las mismas fueron menores (en 39 pacientes, $54.9 \%$ ) y tan solo 3 pacientes presentaron alguna complicación mayor (4.2\%) (Tabla II, Gráfico 1). En el grupo de complicaciones menores incluimos: seroma, hematoma, dehiscencia de la herida, cicatriz patológica del sitio donante (Fig. 1), laxitud aponeurótica, hernia abdominal (Fig. 2), necrosis del colgajo de la abdominoplastia, infección local, necrosis grasa y cutánea parcial del colgajo de TRAM (Fig. 3), necrosis de los colgajos de mastectomía y cicatriz patológica del sitio receptor (Fig. 4). Entre las complicaciones mayores incluimos: atelectasia pulmonar, tromboembolismo pulmonar, trombosis venosa profunda y necrosis total del colgajo TRAM (Fig. 5).

Al dividir las complicaciones según el área afectada, encontramos los siguientes datos: 21 pacientes $(29.5 \%)$ presentaron complicación en el sitio donante del colgajo; $32(45 \%)$ presentaron alguna complicación del colgajo, 

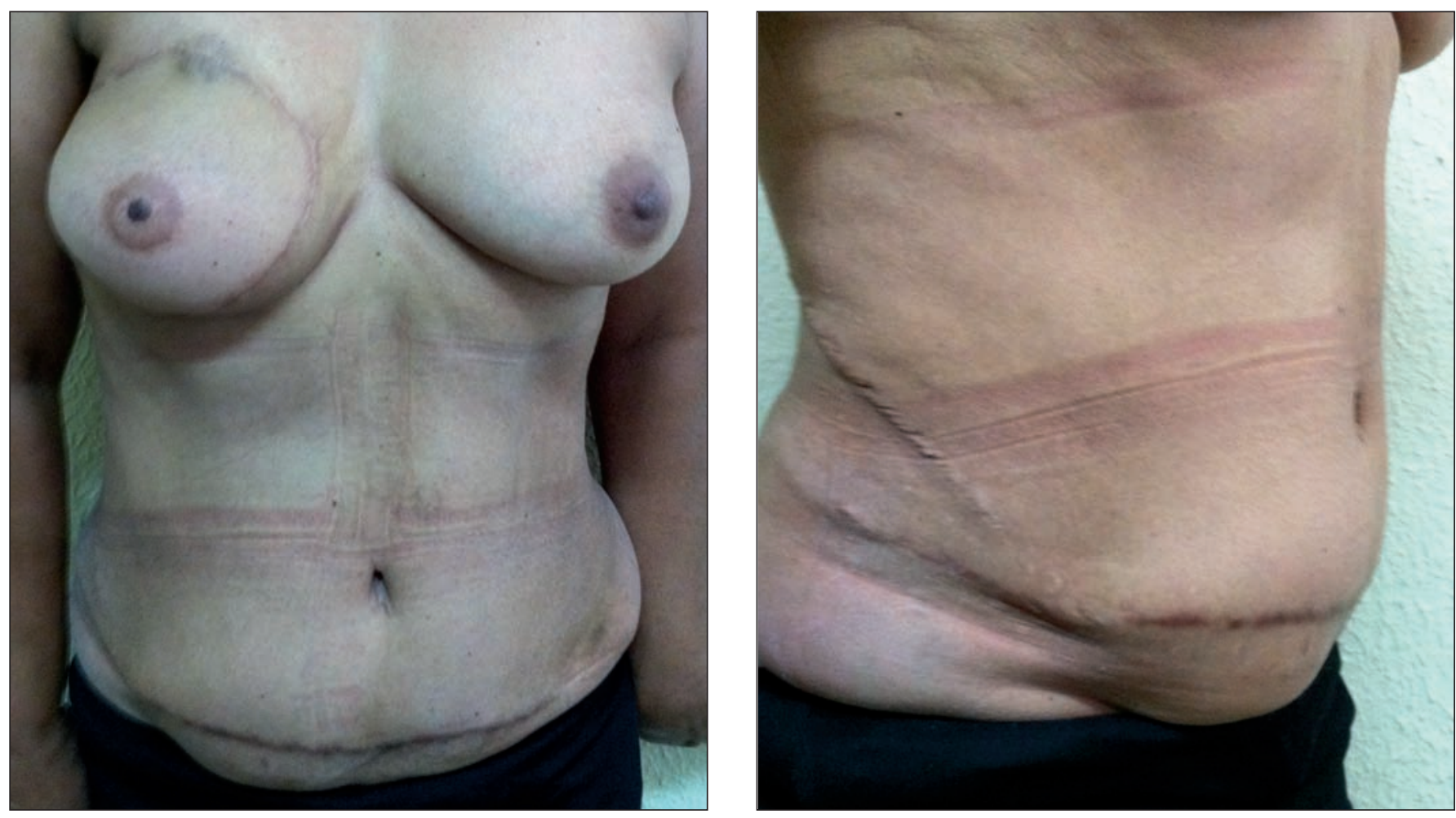

Fig. 2. Paciente de 52 años que desarrolla hernia en el cuadrante inferior derecho abdominal 9 meses después de la realización de colgajo TRAM pediculado ipsilateral. A Vista anterior; B. Vista lateral donde se observa mejor el aumento de volumen en el abdomen bajo

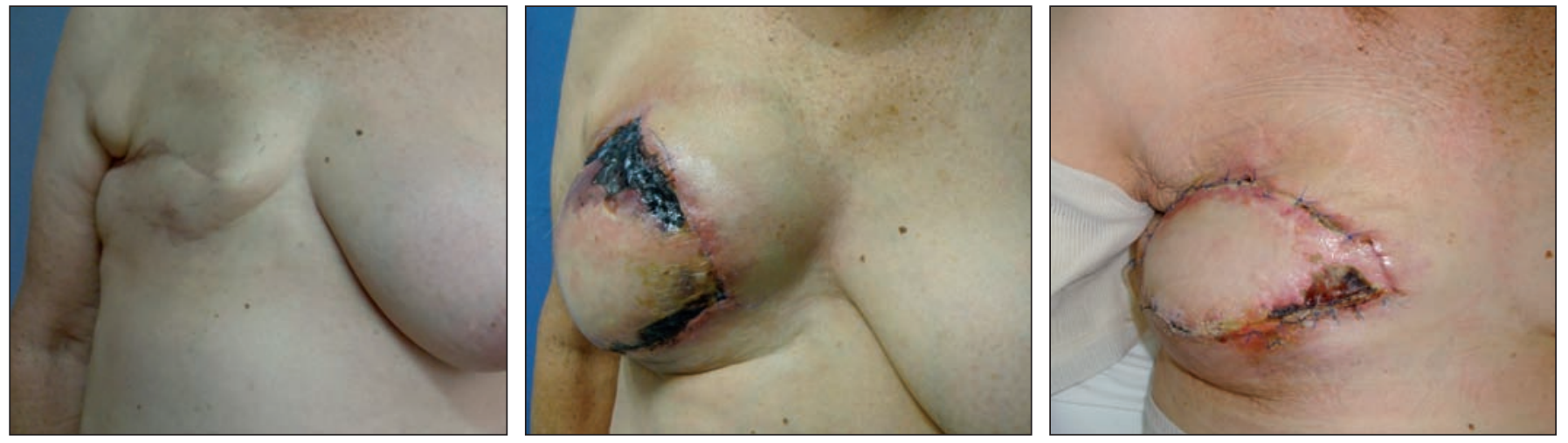

Fig. 3. Paciente de 64 años con antecedente de quimioterapia que desarrolla necrosis grasa y cutánea parcial del colgajo TRAM. A. Preoperatorio; B. Postoperatorio del colgajo TRAM a los 10 días; C. Postoperatorio a los 17 días y 1 semana después de desbridamiento y remodelación del colgajo

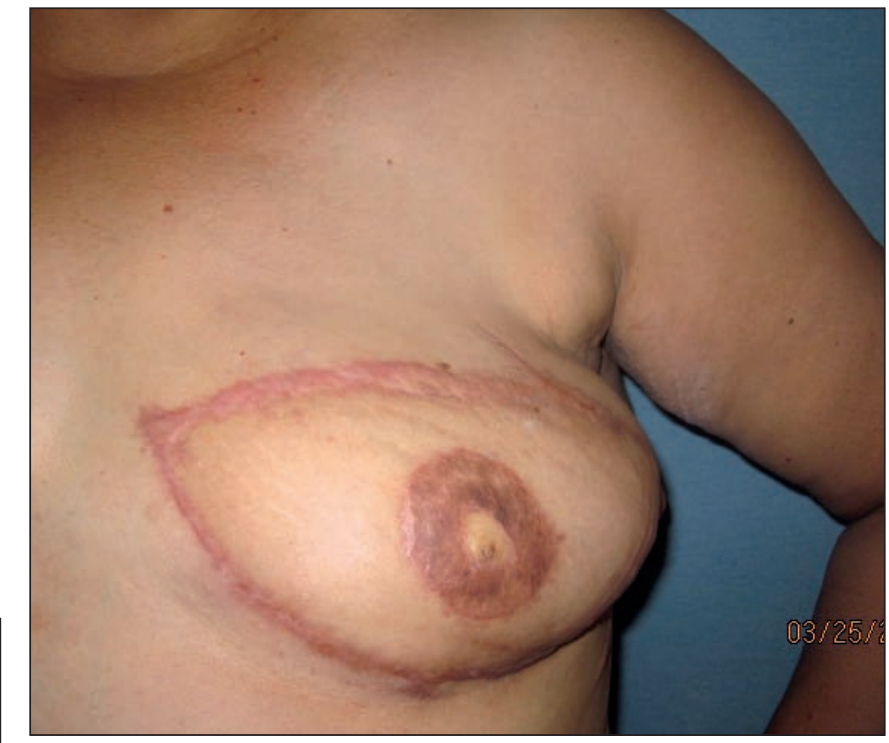

Fig. 4. Paciente de 52 años que desarrolla cicatriz patológica hipertrófica del sitio receptor a los 3 meses del postoperatorio.

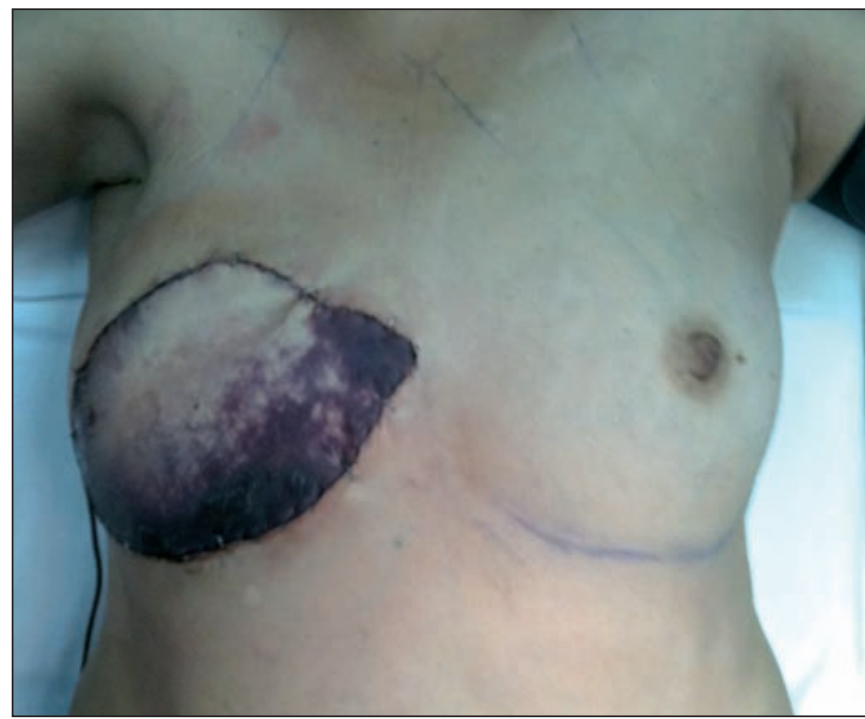

Fig. 5. Paciente de 50 años con antecedentes de quimio y radioterapia preoperatorias que desarrolla necrosis total del colgajo TRAM. Imagen al tercer día de postoperatorio. 
Tabla III. Complicaciones dependiendo del sitio afectado

\begin{tabular}{|l|c|c|}
\hline \multicolumn{1}{|c|}{ Complicaciones } & Frecuencia & Número de pacientes \\
\hline Sitio donante & $29.50 \%$ & 21 \\
\hline Colgajo & $45 \%$ & 32 \\
\hline Sistémicas & $2.80 \%$ & 2 \\
\hline
\end{tabular}

Gráfico 2. Frecuencia de complicaciones dependiendo del sitio afectado

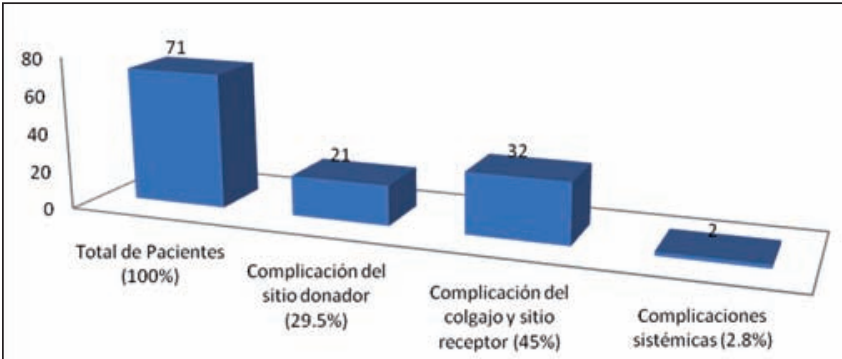

- Complicaciones dependiendo del sitio afectado

Tabla IV. Todas las complicaciones estudiadas y su frecuencia de aparición

\begin{tabular}{|c|c|c|}
\hline Complicaciones & $\begin{array}{l}\text { Número de } \\
\text { pacientes }\end{array}$ & Frecuencia \\
\hline \multicolumn{3}{|l|}{ Del sitio donante } \\
\hline Seroma & 1 & $1.41 \%$ \\
\hline Hematoma & 0 & $0 \%$ \\
\hline Dehiscencia de herida qca. & 7 & $9.86 \%$ \\
\hline Cicatriz patológica & 4 & $5.63 \%$ \\
\hline Laxitud de pared abdominal & 3 & $4.23 \%$ \\
\hline Hernia abdominal & 7 & $9.86 \%$ \\
\hline $\begin{array}{l}\text { Necrosis del colgajo de } \\
\text { abdominoplastia }\end{array}$ & 3 & $4.23 \%$ \\
\hline Infección local & 0 & $0 \%$ \\
\hline \multicolumn{3}{|l|}{ Del colgajo } \\
\hline Seroma & 2 & $2.82 \%$ \\
\hline Hematoma & 1 & $1.41 \%$ \\
\hline Dehiscencia de herida qca. & 8 & $11.27 \%$ \\
\hline Cicatriz patológica & 3 & $4.23 \%$ \\
\hline Necrosis grasa parcial del colgajo & 17 & $23.94 \%$ \\
\hline Necrosis cutánea parcial del colgajo & 15 & $21.13 \%$ \\
\hline Necrosis total del colgajo & 1 & $1.41 \%$ \\
\hline $\begin{array}{l}\text { Necrosis de los colgajos de } \\
\text { mastectomía }\end{array}$ & 6 & $8.45 \%$ \\
\hline Infección local & 3 & $4.23 \%$ \\
\hline \multicolumn{3}{|l|}{ Sistémicas } \\
\hline Atelectasia & 1 & $1.41 \%$ \\
\hline Tromboembolia & 1 & $1.41 \%$ \\
\hline Trombosis venosa profunda & 0 & $0 \%$ \\
\hline Muerte & 1 & $1.41 \%$ \\
\hline
\end{tabular}

Gráfico 3. Todas las complicaciones estudiadas y número de pacientes afectadas de un universo de 71 mujeres reconstruidas con colgajo TRAM pediculado en el Hospital Central Sur de Alta Especialidad (México DF)

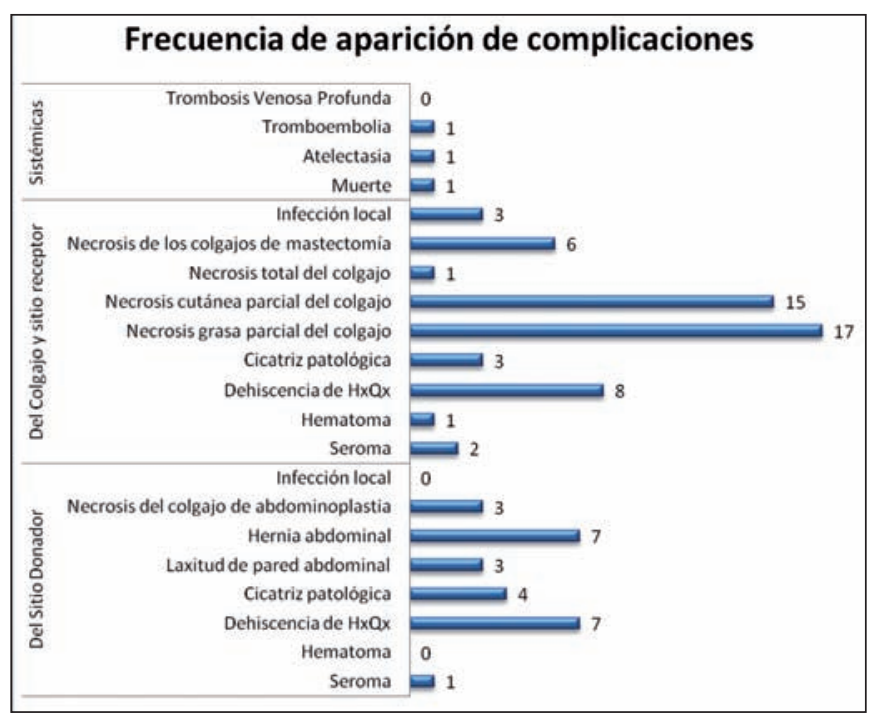

y $2(2.8 \%)$ tuvieron complicación sistémica (Tabla III, Gráfico 2). El aumento en los porcentajes se debe a que cada paciente pudo haber presentado más de una complicación de forma simultánea.

La complicación más frecuente del sitio donante fue la aparición de hernia abdominal (7 pacientes, 9.86\%). La complicación más frecuente del colgajo y sitio receptor fue la necrosis grasa parcial (17 pacientes, 23.94\%). Las únicas complicaciones sistémicas fueron atelectasia y tromboembolismo pulmonar, con 1 caso cada una. El caso que presentó tromboembolismo pulmonar derivó en la muerte de la paciente. La tabla IV y el Gráfico 3 muestran todas las complicaciones y la frecuencia con que se presentaron.

Al realizar el analisis bivariado con la prueba exacta de Fisher comparando el hábito tabáquico frente a las complicaciones del colgajo, encontramos una diferencia estadísticamente significativa entre las pacientes fumadoras y las no fumadoras ( $\mathrm{p}=0.041)$. Del total de las pacientes con hábito tabáquico, (7 pacientes) el $85 \%$ (6 pacientes) tuvo complicaciones del colgajo, en comparación con solo el $40 \%$ de las no fumadoras. En conclusión, el tabaquismo en nuestras pacientes es un factor que muestra un incremento significativo de las complicaciones del colgajo. En general, las pacientes fumadoras tuvieron 2 veces más riesgo de complicarse en comparación con las no fumadoras.

Comparamos también el hecho de recibir o no radioterapia y las complicaciones postoperatorias en general. Encontramos una diferencia estadísticamente significativa ( $\mathrm{p}=0.021)$, con tendencia a mostrar más complicaciones en las pacientes que recibieron radioterapia; es decir, 20 de 25 pacientes (80\%) tuvieron complicaciones en comparación con el $50 \%$ de las que no recibieron radioterapia. Las pacientes con radioterapia en nuestro estudio tuvieron por tanto un incremento del $30 \%$ las complicaciones totales en comparación con las pacientes que no la recibieron. El hecho de recibir radioterapia incrementa 4 veces el riesgo de complicación. 
Gráfico 4. Complicaciones en pacientes que recibieron radioterapia preoperatoria $(n=5)$, postoperatoria $(n=19)$ y ambas $(n=1)$

\section{Complicaciones en Pacientes que recibieron Radioterapia}

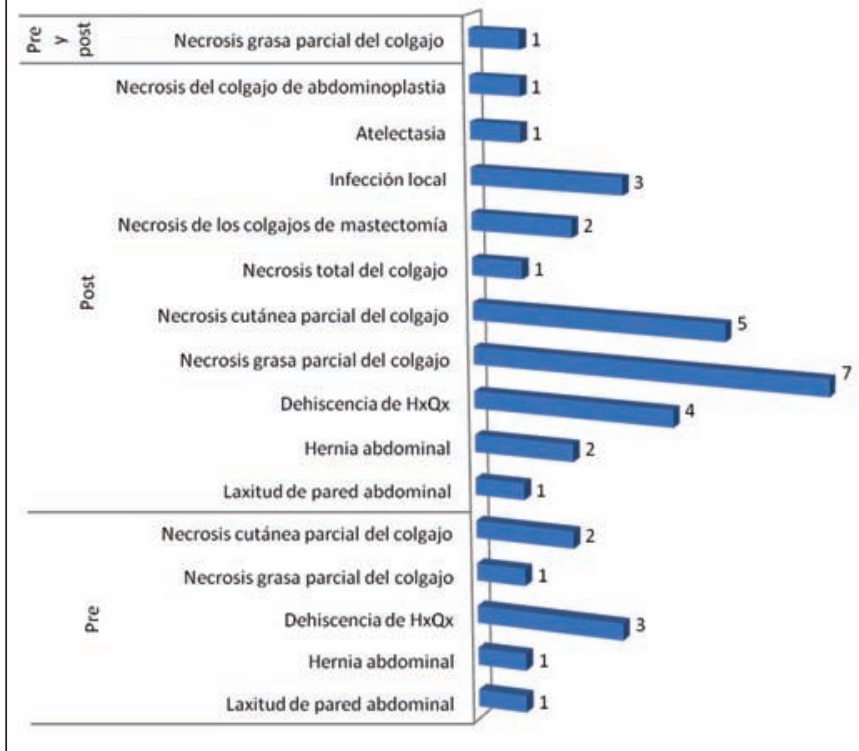

Al separar las pacientes que recibieron radioterapia preoperatoria, postoperatoria, o ambas, encontramos los siguientes datos: la frecuencia de complicaciones en general, en las pacientes que recibieron radioterapia preoperatoria fue del $100 \%(n=5)$, es decir, todas se complicaron. De ellas, 2 tuvieron complicaciones relacionadas con el sitio donante y 3 presentaron complicaciones del colgajo. La paciente que recibió radioterapia preoperatoria y postoperatoria $(n=1)$, también tuvo complicación postoperatoria, específicamente del colgajo (necrosis grasa parcial). Con respecto a las pacientes que sólo recibieron radioterapia en el postoperatorio (que fueron 19) ,14 (73\%) tuvieron complicaciones en general: 5 con complicaciones del sitio donante, 10 con complicaciones del colgajo y 1 con complicación sistémica. El Gráfico 4 ilustra cuáles fueron las complicaciones que aparecieron en cada grupo, siendo la más frecuente la necrosis grasa parcial del colgajo.

Por medio de la prueba de $\mathrm{x}^{2}$ (chi cuadrado), comparamos el hecho de haber recibido quimioterapia o no y las complicaciones en general, encontrando que de las 43 pacientes que recibieron quimioterapia, ya fuera preoperatoria, postoperatoria, o ambas, 32 presentaron alguna complicación $(74.4 \%)(\mathrm{p}=0.003)$ en comparación con el $39 \%$ de las que no recibieron quimioterapia (11 de 28 pacientes). La mayoría de las complicaciones observadas fueron del colgajo, con una diferencia estadísticamente significativa ( $\mathrm{p}=0.024)$; es decir, las pacientes que recibieron quimioterapia mostraron una prevalencia de complicaciones del $55 \%$ en comparación con el $28 \%$ de las que no recibieron quimioterapia.

Con la prueba exacta de Fisher comparamos el hecho de recibir quimioterapia o no y la presencia de necrosis grasa, encontrando que el $32 \%$ de las pacientes presentaban esta complicación en comparación con el 10\% de las
Gráfico 5. Complicaciones en pacientes que recibieron quimioterapia preoperatoria $(n=11)$, postoperatoria $(n=27)$ y ambas $(n=5)$. (Tomar en consideración que pudo presentarse más de una complicación en una misma paciente)

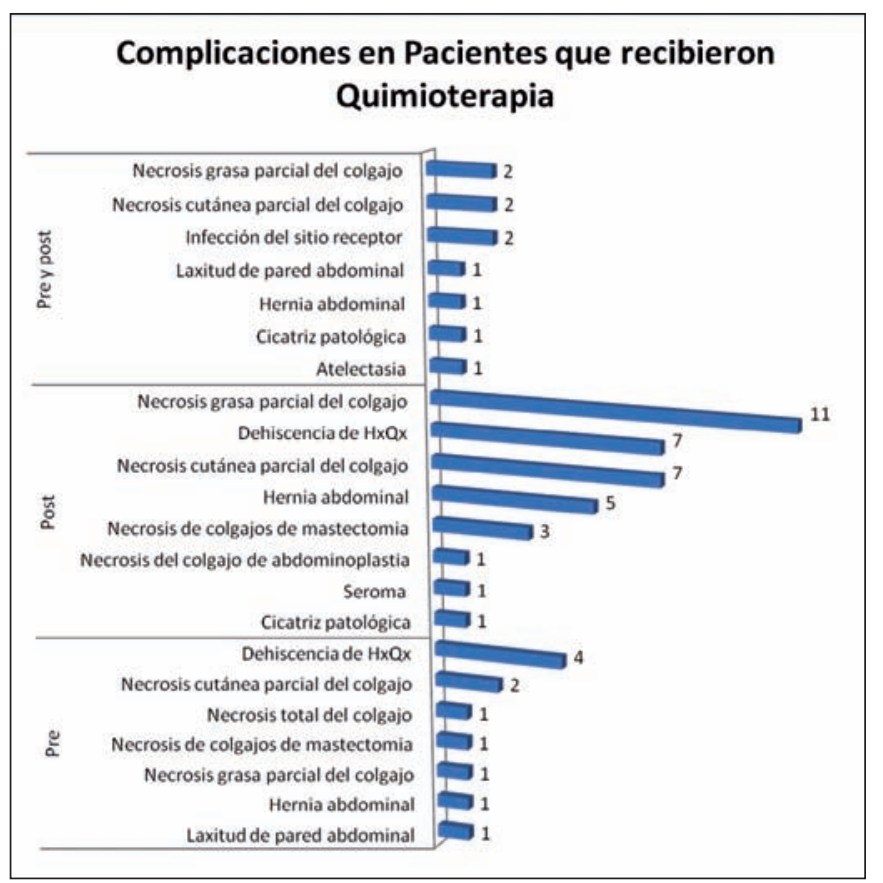

que no recibieron quimioterapia, con una diferencia estadísticamente significativa $(\mathrm{p}=0.047)$. Por lo tanto vimos que las complicaciones, en general, fueron más frecuentes en las pacientes que recibieron quimioterapia (32 de $43,74 \%$ ) en comparación con las que no la recibieron (11 de $28,39 \%$ ), con un riesgo 1.8 veces mayor de presentar alguna complicación al recibir la quimioterapia. Las complicaciones del colgajo también fueron más frecuentes en las pacientes que recibieron quimioterapia, con un incremento en el riesgo de casi 2 veces (1.96).

Al separar las pacientes que recibieron quimioterapia preoperatoria, postoperatoria, o ambas, encontramos los siguientes datos: la frecuencia de complicaciones en general en las 11 pacientes que recibieron quimioterapia preoperatoria fue de $63 \%(n=7)$, siendo la dehiscencia de la herida quirúrgica la más frecuente. De las 27 pacientes que recibieron quimioterapia postoperatoria, el $74 \%$ tuvo alguna complicación $(n=20)$. La necrosis grasa parcial apareció con mayor frecuencia en este grupo. Finalmente, todas las pacientes que recibieron tanto quimioterapia preoperatoria como postoperatoria presentaron alguna complicación $(100 \%, \mathrm{n}=5)$. El Gráfico 5 ilustra las complicaciones que aparecieron en cada grupo.

\section{Discusión}

Diversos autores (2-9) recogen complicaciones en sus series de pacientes sometidas a reconstrucción mamaria con colgajo TRAM; sin embargo, dichos estudios presentan resultados muy variables. El presente trabajo pretende definir con qué frecuencia se presentan complicaciones tras la cirugía de reconstrucción mamaria postcáncer con colgajo TRAM pediculado, tomando en cuenta la mayor cantidad de variables posibles. 
Observamos una frecuencia de complicaciones de $59.15 \%$ que corresponde a 42 pacientes. De éstas, la mayoría correspondieron a complicaciones consideradas como menores $(54.9 \%, \mathrm{n}=39)$. Tan sólo 3 pacientes resultaron con complicación mayor, de las cuales 1 (tromboembolismo pulmonar), derivó en la muerte de la paciente.

La necrosis de piel y grasa es una complicación relativamente común en cualquier reconstrucción con colgajo TRAM, ya sea libre o pediculado. Algunos artículos mencionan desde un 4 hasta un 58.5\% (2-9); esto incluye una serie realizada en la Emory Clinic, que mostró una incidencia de necrosis grasa del $10.6 \%$ (10) y un estudio en el M.D. Anderson Cancer Center en el que Kroll (11) compara la evidencia clínica y radiológica de necrosis grasa entre 49 colgajos TRAM libres y 67 pediculados. El colgajo TRAM libre mostró $8.2 \%$ de incidencia de necrosis grasa en comparación con un $26.9 \%$ en el colgajo TRAM pediculado $(\mathrm{p}<0.01)$. En otro estudio, Fonseca (12) presenta un $13.58 \%$ de necrosis en una serie de 37 pacientes con colgajo TRAM. Nuestro estudio mostró que el $23.94 \%$ de nuestras pacientes presentó necrosis grasa parcial.

La radioterapia afecta de forma negativa al colgajo TRAM, provocando fibrosis y necrosis grasa. En un estudio de1995, Williams (13) recoge la experiencia en la Emory Clinic con radioterapia administrada antes o después de la reconstrucción mamaria. En el mismo, 19 pacientes recibieron radioterapia postoperatoria, 108 antes de la reconstrucción y 572 se sometieron a reconstrucción sin recibir radioterapia. El seguimiento promedio fue de 47 meses. Se encontró fibrosis en el 31.6\% de los colgajos radiados, pero no en las pacientes que recibieron radioterapia preoperatoria. La necrosis grasa fue similar en ambos grupos que se sometieron a radiación, con un $17.6 \%$ frente a un $10 \%$ en las pacientes que no recibieron radiación. Rogers (14) encuentra una tendencia similar cuando se exponen los colgajos DIEP libres (Colgajos de perforante de arteria epigástrica profunda) a radioterapia postoperatoria. Por el contrario, Zimmerman (15) describe 21 pacientes con reconstrucción con colgajo TRAM libre y encuentra un muy leve efecto negativo en la mayoría de las pacientes.

En el presente estudio comparamos el hecho de recibir o no radioterapia con las complicaciones postoperatorias en general. Encontramos una diferencia estadísticamente significativa $(\mathrm{p}=0.021)$, con tendencia a mostrar más complicaciones en las pacientes que recibieron radioterapia; es decir 20 de 25 pacientes (80\%) tuvieron complicaciones en comparación con un $50 \%$ de las que no recibieron radioterapia. Las pacientes con radioterapia en nuestro estudio tuvieron un incremento del $30 \%$ de las complicaciones totales en comparación con las pacientes que no la recibieron. El hecho de recibir radioterapia incrementa 4 veces el riesgo de complicación. También encontramos que las pacientes que recibieron radioterapia presentaron con mayor frecuencia necrosis
Gráfico 6. Frecuencia de necrosis grasa parcial del colgajo TRAM en pacientes no radiadas $(n=46)$ y en pacientes con radioterapia preoperatoria $(n=5)$, postoperatoria $(n=19)$ o ambas $(n=1)$

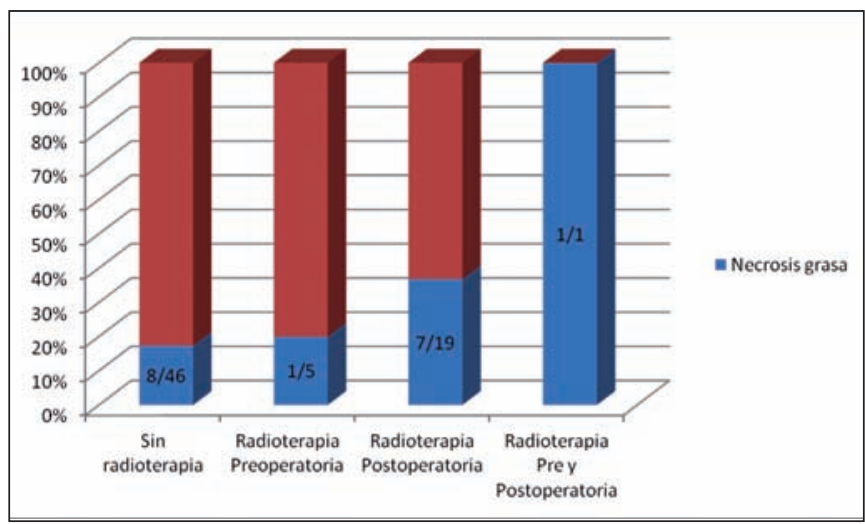

grasa del colgajo TRAM. De las pacientes no radiadas $(\mathrm{n}=46), 8$ presentaron esta complicación $(17.3 \%)$, mientras que la necrosis grasa aumentó su frecuencia al $20 \%$ ( 1 de 5 pacientes) con radioterapia preoperatoria, y a un $36 \%$ (7 de 19 pacientes) con radioterapia postoperatoria. La única paciente que recibió radioterapia tanto pre como postoperatoria también presentó necrosis grasa parcial (100\%). El Gráfico 6 ilustra las diferencias en los porcentajes.

Hartrampf (16) presenta una incidencia de hernias del $1.5 \%$ en 351 reconstrucciones con colgajo TRAM unipediculado. El grupo de Emory recoge una incidencia del $8.8 \%$, cifra afectada por el uso de reparación con malla por un cirujano; desde entonces la cifra se redujo al 3.9\%. Estos datos son similares a los de Petit, (17) que recoge 251 colgajos TRAM con una incidencia de hernia del $7 \%$, ahora reducida al 2\%. En una revisión de 268 pacientes sometidas ya sea a colgajo TRAM libre o a colgajo TRAM pediculado convencional con seguimiento de por lo menos 6 meses, Kroll encuentra tasas similares de hernia en ambos grupos (3.8\% frente a 2.6\%, sin significancia estadística). Nuestra investigación reveló un 9.86\% de hernia abdominal. Al igual que en el caso de nuestros colegas, estas cifras se vieron afectadas por la utilización de malla para la reparación. Cuando no se usó malla, la frecuencia de hernia abdominal fue del $12.8 \%$ (5 pacientes sobre 39), frecuencia que bajó al 6.2\% (2 pacientes sobre 32) cuando se usó malla de polipropileno. Edsander-Nord (18) realiza un estudio prospectivo de 19 colgajos TRAM libres y 23 pediculados, en el que las pacientes sometidas a colgajo libre tuvieron mayor incidencia de laxitud aponeurótica del abdomen bajo (82\%) en comparación con los colgajos pediculados (48\%). En una serie corta de 5 casos de TRAM unipediculado con simetrización simultánea, Giachero (19) menciona la aparición de 1 caso (20\%) de abultamiento abdominal sin hernia. En nuestra casuística, tuvimos una frecuencia del $4.23 \%$ de laxitud aponeurótica.

La pérdida completa del colgajo es extremadamente rara en la reconstrucción mamaria con colgajo TRAM pediculado ( 2 de 350 colgajos unipediculados y 0 de 39 colgajos bipediculados en la serie de Hartrampf) (15). 
Trabulsy y col. (20) notan una incidencia del $6 \%$ de pérdida parcial y del $4 \%$ de pérdida total en su serie de 99 pacientes. En nuestro hospital, tuvimos una paciente con necrosis total del colgajo, lo que representó el $1.41 \%$ del total.

Aunados a la radioterapia, el tabaquismo y la quimioterapia influyeron significativamente en el pronóstico de nuestras pacientes. El tabaquismo mostró un incremento significativo de las complicaciones del colgajo, de manera que vimos cómo las pacientes fumadoras tenían un $40 \%$ más de riesgo de presentar una complicación del colgajo en comparación con las no fumadoras. En general, las pacientes fumadoras tuvieron 2 veces más riesgo de complicarse que las no fumadoras. Además, las complicaciones fueron más frecuentes en las pacientes que recibieron quimioterapia (32 de 43 pacientes, $74 \%$ ) en comparación con las que no la recibieron (11 de 28 pacientes, $39 \%$ ), con un riesgo 1.8 veces mayor de presen-
Gráfico 7. Frecuencia de necrosis grasa parcial del colgajo TRAM en pacientes $\sin$ quimioterapia $(10.7 \%, \mathrm{n}=3 / 28)$ y con quimioterapia preoperatoria $(9.09 \%, n=1 / 11)$, postoperatoria $(55 \%, n=11 / 20)$ o ambas $(40 \%, n=2 / 5)$

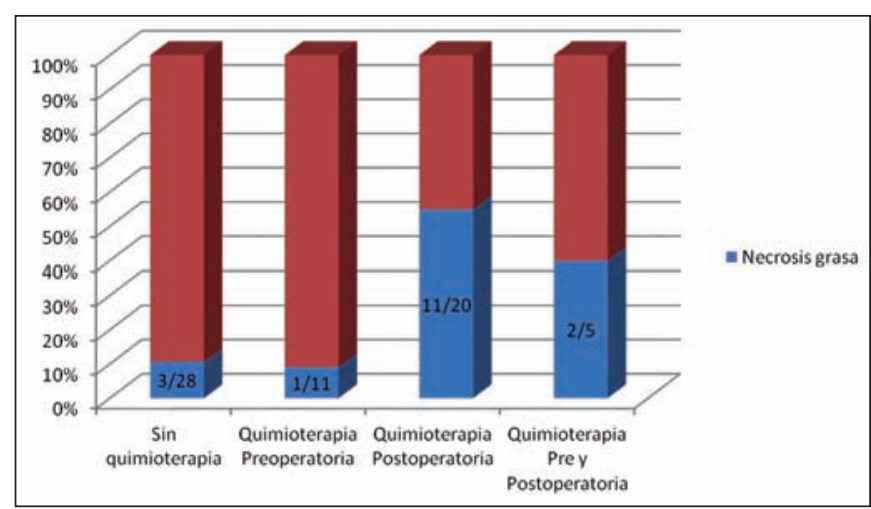

tar alguna complicación al recibir quimioterapia.

Las complicaciones del colgajo también fueron más frecuentes en las pacientes que recibieron quimioterapia,

Tabla V. Resumen de complicaciones recogidas en el Hospital Central Sur de Alta Especialidad (México DF) y en otros centros hospitalarios

\begin{tabular}{|c|c|c|c|c|c|c|c|c|c|}
\hline & $\begin{array}{c}\text { University } \\
\text { of } \\
\text { Rochester } \\
\text { Medical } \\
\text { Center }\end{array}$ & $\begin{array}{c}\text { University } \\
\text { British } \\
\text { Columbia, } \\
\text { Baptist } \\
\text { Hospital }\end{array}$ & $\begin{array}{c}\text { Hospital } \\
\text { General de } \\
\text { México }\end{array}$ & $\begin{array}{l}\text { Hospital } \\
\text { Gea } \\
\text { González }\end{array}$ & $\begin{array}{c}\text { University } \\
\text { of } \\
\text { Michigan } \\
\text { Medical } \\
\text { Center }\end{array}$ & $\begin{array}{c}\text { MD } \\
\text { Anderson } \\
\text { Cancer } \\
\text { Center }\end{array}$ & $\begin{array}{l}\text { Mayo } \\
\text { Clinic }\end{array}$ & $\begin{array}{c}\text { Asian } \\
\text { Medical } \\
\text { Center }\end{array}$ & $\begin{array}{c}\text { Hospital } \\
\text { Central Sur } \\
\text { Pemex }\end{array}$ \\
\hline & Serletti $^{2}$ & Clugston $^{3}$ & Haddad $^{4}$ & Santamaría ${ }^{5}$ & Alderman $^{6}$ & Scevola $^{7}$ & Garvey $^{8}$ & $\mathrm{Kim}^{9}$ & López \\
\hline & 1997 & 2000 & 2001 & 2001 & 2002 & 2002 & 2006 & 2009 & 2012 \\
\hline \multicolumn{10}{|l|}{ SITIO DONANTE } \\
\hline Seroma & & 9.5 & 3.4 & & 3.9 & 3.2 & 7.4 & 2 & 1.41 \\
\hline Hematoma & 4 & & & & 3.9 & & 7.4 & 0.2 & 0 \\
\hline Dehiscencia de la herida & & & 3.4 & 14.5 & & & 23.4 & 1.4 & 9.86 \\
\hline Cicatriz patológica & & & & & & & & 5.2 & 5.63 \\
\hline Hernia abdominal & 6 & & 5.8 & & 7.8 & & 16 & & 9.86 \\
\hline Necrosis del colgajo de abdominoplastía & & 10.5 & & & 1.7 & & 23.4 & 3.2 & 4.23 \\
\hline Infección local & 8 & 3.7 & 3.4 & & 11.7 & 0.7 & 11.7 & 1 & 0 \\
\hline \multicolumn{10}{|l|}{ COLGAJO Y SITIO RECEPTOR } \\
\hline Seroma & & & & & 3.9 & 7.8 & 13.8 & 1 & 2.82 \\
\hline Hematoma & 4 & 1.6 & 2.3 & & 3.9 & & 13.8 & 2 & 1.41 \\
\hline Dehiscencia de la herida & & & & & 5.6 & & 13.8 & 1 & 11.27 \\
\hline Cicatriz patológica & & & & & & & & 2.6 & 4.23 \\
\hline Necrosis grasa parcial & 4 & 7.1 & 4.6 & 52.3 & 16.2 & & 58.5 & 14.2 & 23.94 \\
\hline Necrosis total & 1.9 & 0 & 2.3 & 0 & 1.1 & & 8.5 & 0.2 & 1.41 \\
\hline Necrosis de los colgajos de mastectomía & & 9.4 & & & & & & & 8.45 \\
\hline Infección local & 8 & 3.7 & & & 11.7 & 1.8 & 17 & 0.8 & 4.23 \\
\hline \multicolumn{10}{|l|}{ SISTÉMICAS } \\
\hline Atelectasia pulmonar & & & & & & & & 0.2 & 1.41 \\
\hline Tromboembolia pulmonar & & 1.1 & & & & & & 1.6 & 1.41 \\
\hline Trombosis venosa profunda & 2 & 1.1 & & & & & & & 0 \\
\hline
\end{tabular}


con un incremento en el riesgo de casi 2 veces (1.96). Cuando analizamos específicamente la aparición de necrosis grasa parcial del colgajo, encontramos una frecuencia del $10.7 \%(\mathrm{n}=3)$ en las pacientes que no recibieron quimioterapia (28 pacientes), mientras que de las 11 pacientes que recibieron quimioterapia preoperatoria, solo 1 presentó esta complicación (9.09\%). Pero cuando la quimioterapia se administró de forma postoperatoria o combinada, la frecuencia de necrosis grasa parcial del colgajo fue del 55\% (11 de 20 pacientes) y del $40 \%$ ( 2 de 5 pacientes) respectivamente. El Gráfico 7 ilustra mejor estos hallazgos.

La Tabla V resume la frecuencia de complicaciones encontradas en nuestro estudio y compara las recogidas por algunos otros autores. Cabe mencionar que nuestro objetivo no es el hacer un estricto análisis comparativo con lo presentado en otros estudios, dada la amplia variabilidad en las definiciones operacionales de las variables y las distintas características poblacionales y de técnicas quirúrgicas; sin embargo, consideramos que estos datos pueden ser ilustrativos.
Aunque nuestro análisis demuestra la influencia de factores de riesgo como el tabaquismo, la radioterapia y la quimioterapia en la aparición de complicaciones en la reconstrucción mamaria con colgajo TRAM pediculado, dichos resultados deben tomarse con cautela debido a algunas limitaciones del estudio que incluyen: un diseño de estudio transversal (menor peso que uno de cohorte), datos obtenidos de los expedientes (podrían implicar algún sesgo) y un tamaño muestral pequeño.

\section{Conclusiones}

Analizamos la experiencia en el uso de colgajo TRAM pediculado para reconstrucción mamaria tras cáncer en el Hospital Central Sur de Alta Especialidad de la Ciudad de México, teniendo como objetivo general conocer la frecuencia de complicaciones en las pacientes tratadas por el Servicio de Cirugía Plástica y Reconstructiva en un periodo de 7 años. El resumen de las complicaciones encontradas en nuestras pacientes permite
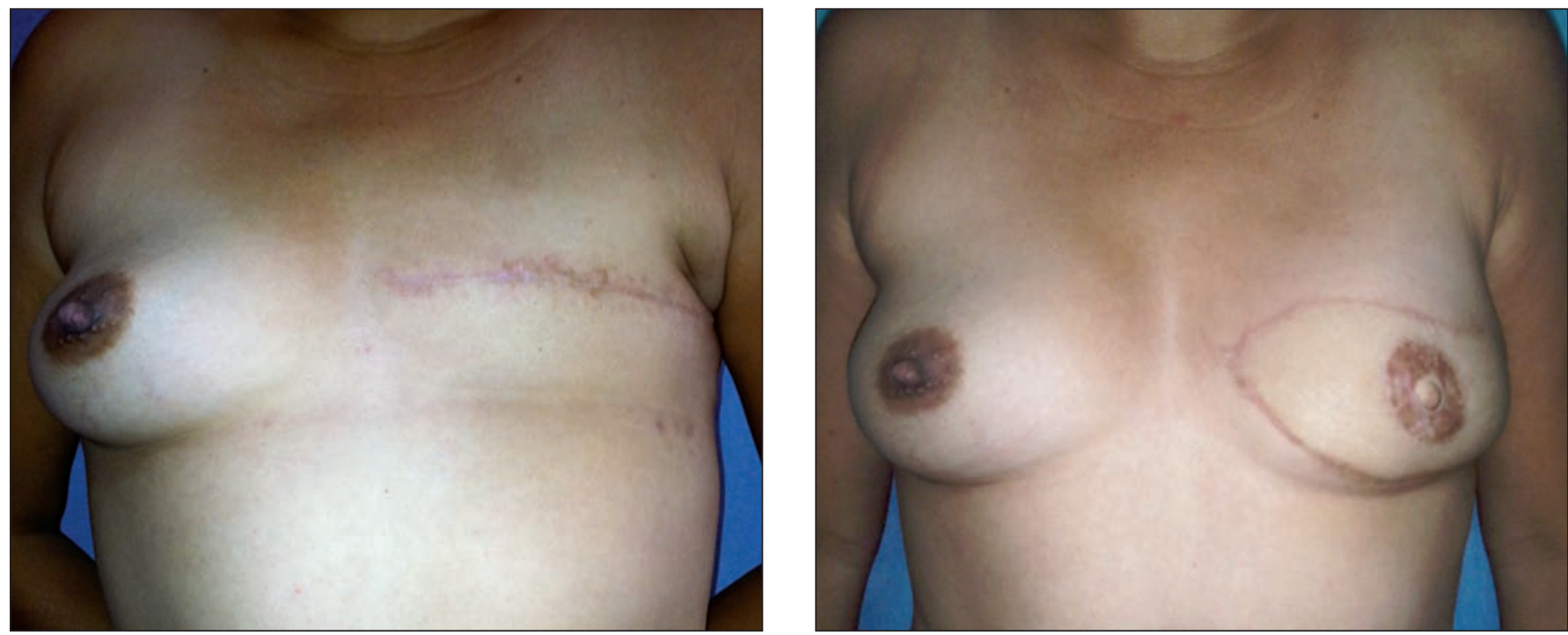

Fig. 6. Paciente de 39 años reconstruida con colgajo TRAM pediculado ipsilateral tardío. A. Preoperatorio; B. Postoperatorio a los 12 meses.
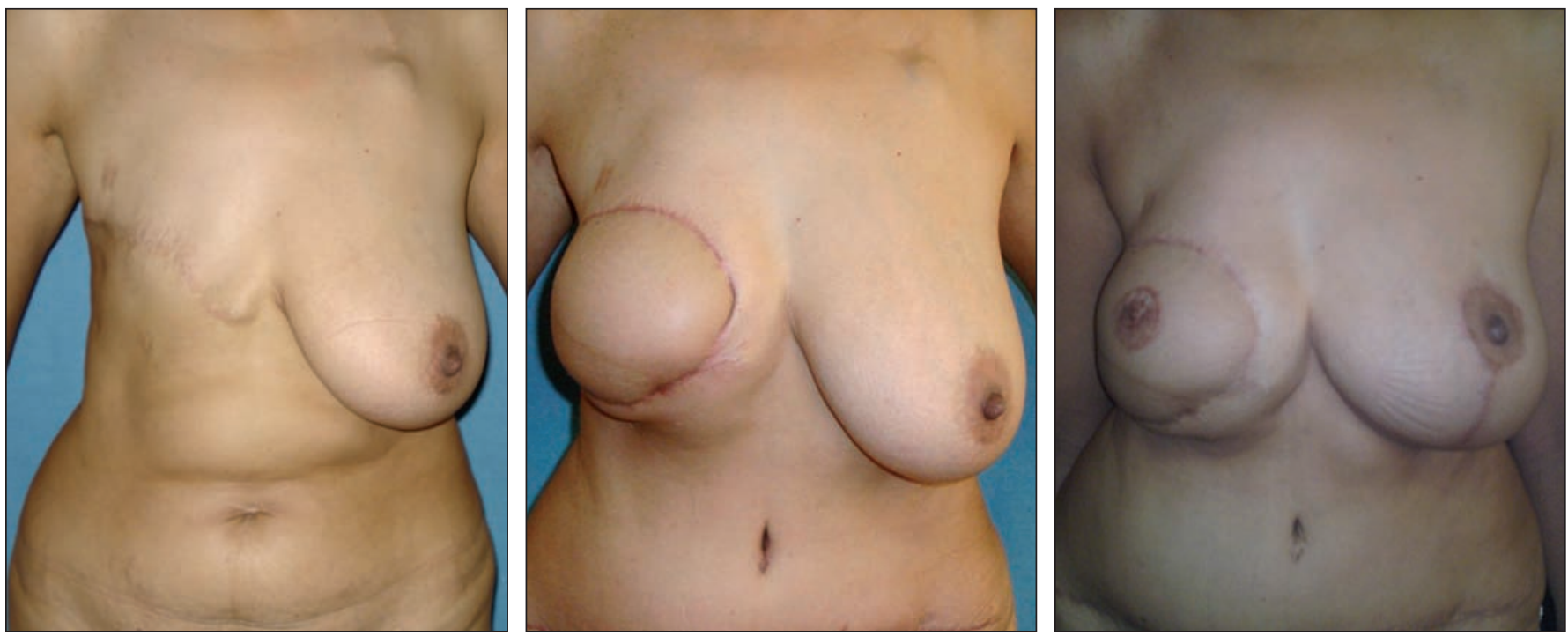

Fig. 7. Paciente de 46 años reconstruida con colgajo TRAM pediculado ipsilateral tardío. A. Preoperatorio; B. Postoperatorio a los 6 meses; C. Postoperatorio a los 12 meses del colgajo, 6 meses después de reconstrucción del complejo pezón-areola y mastopexia contralateral para simetrización. 


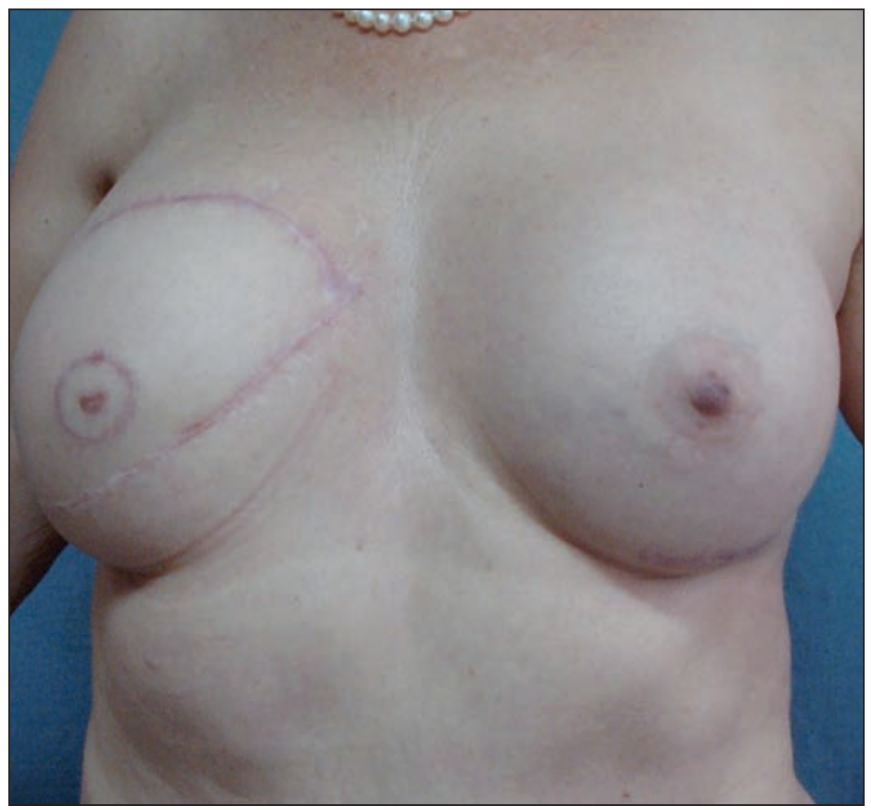

Fig. 8. Paciente de 56 años de edad reconstruida con colgajo TRAM pediculado ipsilateral tardío. Resultado postoperatorio 8 meses después del colgajo y 5 meses después de reconstrucción del complejo pezón- areolay aumento mamario contralateral con implante redondo de $210 \mathrm{cc}$ para simetrización.

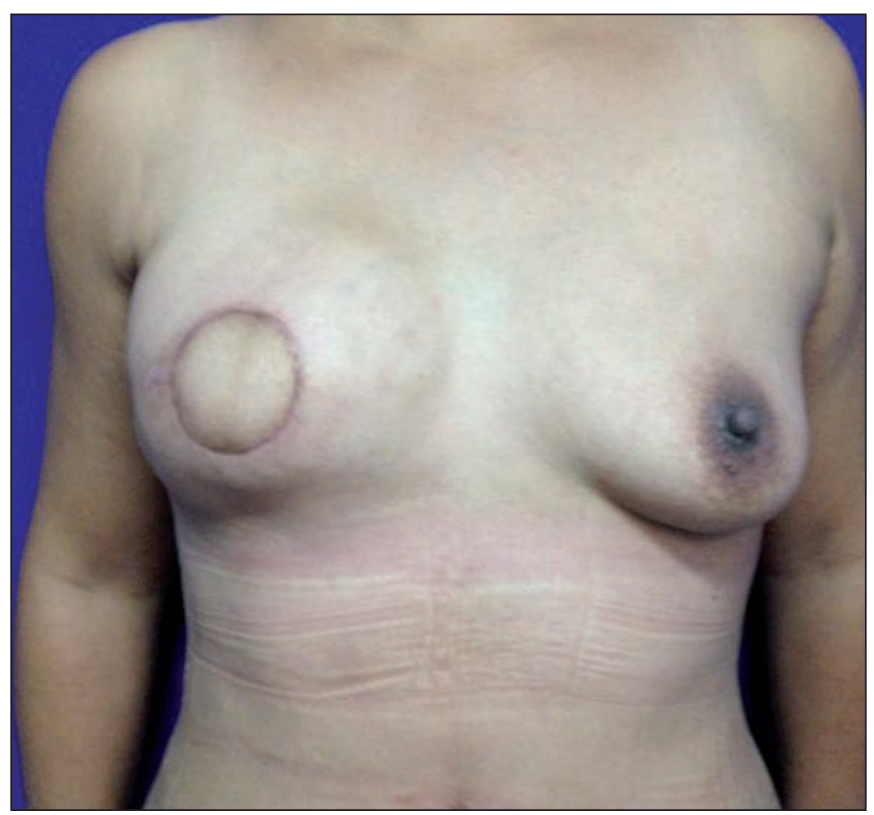

Fig. 9. Postoperatorio en paciente de 41 años de edad, 6 semanas después de reconstrucción mamaria con colgajo TRAM pediculado ipsilateral tardío.

concluir que la frecuencia de su aparición es consistente con lo publicado en la literatura nacional e internacional al respecto.

En nuestra práctica habitual, el colgajo TRAM pediculado sigue siendo hasta el momento el estándar de oro en reconstrucción mamaria, considerándolo un procedimiento mayor no exento de complicaciones. Afortunadamente, la mayoría de dichas complicaciones son menores y el resultado estético es adecuado (Fig. 6-9). El conocer las características de las pacientes de nuestro hospital, cuáles son sus complicaciones y cuáles los factores de riesgo que influyen en el resultado de sus cirugías, nos permite mejorar la calidad en la atención de aquellas pacientes que se someten en nuestro centro a reconstrucción mamaria con tejidos autólogos.

\section{Dirección del autor}

Dr. José Luis López Robles

Hospital Ángeles Culiacán.

Blvd. Alfonso G. Calderón no. 2193, consultorio 503-A

Desarrollo Urbano Tres Ríos

Culiacán, Sinaloa. CP 80020. México.

e-mail: dr_jllr@hotmail.com

Agradecimientos

A los Drs. Francisco Javier Carrera Gómez, Cuahutémoc Márquez Espriella, Marco Antonio Cuervo Vergara y Luis Ernesto Ramos Durón, cirujanos plásticos del Hospital Central Sur de Alta Especialidad.

\section{Bibliografía}

1. 1. Gutiérrez Salgado J.E.: TRAM pediculado: La prueba del tiempo en reconstrucción mamaria. Cir Plast 2011;21(1):45-52.

2. Serletti, J. M., Moran, S. L.: Free versus the pedicled TRAM flap: A cost comparison and outcome analysis. Plast Reconstruct Surg. 1997; 100(6): 1418-1424.

3. Clugston P.A., Gingrass M.K., Azurin D., Fisher J., Maxwell G.P.: Ipsilateral TRAM flaps: the safer alternative? Plast Reconstruct Surg. 2000; 105(1): 77-82.

4. Haddad Tame J.L., Torres Gómez B., Bello Santamaría J.A., et al.: Reconstrucción mamaria en el servicio de cirugía plástica en el Hospital General de México. Rev Med Hosp Gen Mex. 2001; 64(4): 210-219.

5. Santamaría Linares E., Ramírez Ugalde M.T., Ochoa Carrillo F., Fuentes Alburo A.: Reconstrucción mamaria con colgajo TRAM libre. ¿Se justifica el riesgo? Cir Plast. 2001; 11(2): 49-60.

6. Alderman A.K., Wilkins E.G., Kim H.M., Lowery J.C.: Complications in postmastectomy breast reconstruction: Two Year results of the Michigan Breast Reconstruction Outcome Study. Plast Reconstruct Surg. 2002; 109(7): 2265-2274.

7. Scevola S., Youssef A., Kroll S.S., Langstein H.: Drains and seromas in TRAM flap breast reconstructions. Ann Plast Surg. 2002; 48(5): 511-514.

8. Garvey P.B., Buchel E.W., Pockaj B.A., et al.: Diep and pedicled TRAM flaps: A comparison of outcomes. Plast Reconstruct Surg. 2006; 117(6): 1711-1719.

9. Kim E.K., Eom J.S., Ahn S.H., Son B.H., Lee T.J.: Evolution of the pedicled TRAM flap, a prospective study of 500 consecutive cases by a single surgeon in asian patients. Ann Plast Surg. 2009; 63(4): 378-382.

10. Watterson P.A., Bostwick J. III, Hester T.R. Jr., Bried J.T., Taylor G.I.: TRAM flap anatomy correlated with a 10-year clinical experience with 556 patients. Plast Reconstr Surg. 1995; 95(7): 1185-1194.

11. Kroll S.S., Gherardini G., Martin JE, et al.: Fat necrosis in free and pedicled TRAM flaps. Plast Reconstr Surg. 1998; 102(5): 1502-1507.

12. Fonseca Portilla, G. and Vargas Naranjo, S.: Recons- 
trucción mamaria en el Hospital S. Juan de Dios de Costa Rica: un estudio transversal. Cir. plást. iberolatinoam. 2006; 32(2): 93-98.

13. Williams J.K., Bostwick J. III, Bried J.T., Mackay G., Landry J., Benton J.: TRAM flap breast reconstruction after radiation treatment. Ann Surg. 1995; 221(6): 756766.

14. Rogers N.E., Allen R.J.: Radiation effects on breast reconstruction with the deep inferior epigastric perforator flap. Plast Reconstr Surg. 2002; 109(6): 1919-1924.

15. Zimmerman R.P., Mark R.J., Kim A.I., Walton T., Sayah D., Juillard G.F., Nguyen M.: Radiation tolerance of transverse rectus abdominis myocutaneous-free flaps used in immediate breast reconstruction. Am J Clin Oncol. 1998; 21(4): 381-385.

16. Hartrampf CR Jr.: The transverse abdominal island flap for breast reconstruction. A 7-year experience. Clin Plast Surg. 1988; 15(4): 703-716.
17. Petit J.Y., Rietjens M., Garusi C., et al. : Abdominal complications and sequelae after breast reconstruction with pedicled TRAM flap: is there still an indication for pedicled TRAM in the year 2003?. Plast Reconstr Surg. 2003; 112(4): 1063-1065.

18. Edsander-Nord A., Jurell G., Wickman M.: Donor-site morbidity after pedicled or free TRAM flap surgery: a prospective and objective study. Plast Reconstr Surg. 1998; 102(5): 1508-1516.

19. Giachero-Castaño, V. et al.: Reconstrucción mamaria con colgajo músculo-cutáneo transverso de recto abdominal (TRAM) y simetrización simultánea. Cir. plást. iberolatinoam. 2010; 36 (2): 135-144.

20. Trabulsy P.P., Anthony J.P., Mathes S.J.: Changing trends in postmastectomy breast reconstruction: a 13 year experience. Plast Reconstr Surg. 1994; 93(7): 1418-1427. 